\title{
APLIKASI PELAYANAN ANTRIAN DI APOTEK DHEA BERBASIS WAP (WIRELESSS APPLICATION PROTOCOL) DAN SMS GATEWAY
}

\author{
Dede Irawan*1, Intan Rahmiawati ${ }^{2}$ \\ ${ }^{1}$ Universitas Kuningan \\ ${ }^{2,3}$ Sistem Informasi Universitas Kuningan

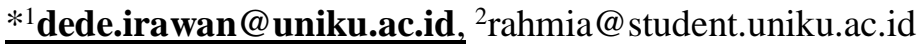

\begin{abstract}
Abstrak
Saat ini, masih banyak instansi /perusahaan yang belum memanfaatkan teknologi untuk memberikan kemudahan bagi para pemakainya khususnya dalam pelayanan antrian. Seperti hal nya di Apotek Dhea, di Apotek ini terdapat beberapa layanan klinik kesehatan diataranya: klinik kandungan, anak, gigi dan THT. Terkadang pasien memesan terlebih dahulu nomor antrian untuk mendapatkan antrian lebih awal, fenomena ini terjadi karena adanya perbedaan waktu antara pelayanan klinik kesehatan yang mengharuskan pasien memesan terlebih dahulu antrian sebelum waktu pemeriksaan, hal ini lah yang menjadi acuan pembuatan aplikasi pelayanan antrian.Aplikasi pelayanan antrian ini adalah suatu cara tertentu untuk memberikan pelayanan yang terbaik. Pelayanan terbaik tersebut diantaranya adalah memberikan pelayanan yang cepat sehingga pasien tidak dibiarkan menunggu terlalu lama. Aplikasi pelayanan antrian ini memberikan kemudahan bagi pasien, pasien dapat mengakses antrian yang dapat dipesan melalui telepon seluler dengan format WAP (Wireless Application Protocol) dan informasi antrian akan disampaikan kepada pasien melalui format SMS Gateway.Maka, dengan adanya aplikasi ini akan memberi kemudahan pasien dalam melakukan pendaftaran antrian, pasien dapat mengakses pelayanan pendaftaran antrian dan informasi klinik kesehatan secara Mobile yang dapat di akses setiap saat hanya dengan menggunakan ponsel yang akan berpengaruh terhadap pengolahan data pemesanan antrian sehingga lebih mudah dan efektif.
\end{abstract}

Kata kunci: Pelayanan Antrian, Apotek Dhea, WAP, SMS Gateway

\begin{abstract}
In this time, there are still many institutions / companies which have not yet used technology to give ease for all user especially in queue service such as Apotek Dhea. In this drugstore, there are some health service such as : obstetrical, child, tooth clinics. Sometimes patient orders before they have queue number to get earlier queue. This phenomenon happens caused by difference of time between service of health clinic and health service in each clinic. This problem becomes reference in making application of queue service. Application service of this queue is a way to give best service. Application of queue service gives ease to patients, they can access this application to order the queue through telephone with WAP ( Wireless Application Protocol) format and queue information will be sent to patient through SMS Gateway format. Hence, this application will give ease to patient in conducting registration of queue, patient can access service of registration in health clinic information and queue by Mobile that can be accessed everywhere, every time by using handphone.
\end{abstract}

Keywords: Queue Service, Apotek Dhea, WAP, SMS Gateway

\section{PENDAHULUAN}

Antrian merupakan salah satu fenomena yang terjadi dalam aktifitas sehari-hari dialami oleh pelanggan. Antrian tidak dikehendaki oleh pelanggan maupun penyedia jasa. Pelanggan menilai waktunya cukup berharga, sehingga 
mereka mungkin akan memilih melakukan perjalanan yang lebih jauh atau mengeluarkan biaya sedikit lebih besar untuk mendapatkan pelayanan yang tidak menyebabkan antrian panjang.

Kehilangan pelanggan tentunya tidak diinginkan oleh penyedia jasa, tetapi memenuhi keinginan pelanggan mengantri sesingkat mungkin atau meminimumkan waktu mengantri sering mengakibatkan penambahan investasi dan biaya operasional.

Fenomena antrian kerap dijumpai dalam kehidupan sehari-hari. khususnya dalam segi pelayanan kesehatan, para pasien menunggu pada suatu klinik kesehatan, seperti halnya Apotek Dhea, di Apotek ini terdapat beberapa layanan klinik kesehatan diataranya: klinik kandungan, anak, gigi dan THT. Terkadang pasien memesan terlebih dahulu nomor antrian untuk mendapatkan antrian lebih awal, fenomena ini terjadi karena adanya perbedaan waktu antara pelayanan klinik kesehatan yang mengharuskan pasien memesan terlebih dahulu antrian sebelum waktu pemeriksaan, hal ini lah yang menjadi acuan pembuatan aplikasi pelayanan antrian. Seiring berkembangnya tekhnologi, kini banyak aplikasi yang memudahkan pelayananan antrian diantaranya aplikasi berbasis web, aplikasi berbasis web tak lepas dari jaringan internet yang sulit di jangkau oleh masyarakat karena dalam penggunaannya aplikasi ini membutukan komputer yang terkoneksi pada jaringan internet yang tidak semua masyarakat mempunyai koneksi jaringan tersebut. Namun, disini penulis memutuskan untuk lebih menggunakan aplikasi berbasis WAP dan SMS Gateway yang mana merupakan layanan yang terdapat dalam telepon genggam (handphone). Saat ini masyarakat sendiri telah menjadikan handphone sebagai kebutuhan untuk berkomunikasi.

Aplikasi pelayanan antrian ini adalah suatu cara tertentu untuk memberikan pelayanan yang terbaik. Pelayanan terbaik tersebut diantaranya adalah memberikan pelayanan yang cepat sehingga pasien tidak dibiarkan menunggu terlalu lama. Aplikasi pelayanan antrian ini memberikan kemudahan bagi pasien, pasien dapat mengakses antrian yang dapat dipesan melalui telepon seluler dengan format WAP (Wireless Application Protocol) dan informasi antrian akan disampaikan kepada pasien melalui format SMS Gateway. Maka berdasarkan latar belakang diatas penulis mengambil judul Skripsi yaitu "Aplikasi Pelayanan Antrian di Apotek Dhea berbasis WAP (Wireless Application Protocol) dan SMS Gateway".

Adapun identifikasi masalah yang akan di bahas pada latar belakang masalah tersebut di atas adalah sebagai berikut :

1. Bagaimana aplikasi pelayanan antrian berbasis WAP dan SMS Gateway ini bisa bemberikan pelayanan antrian secara cepat, efektif dan efesien tanpa harus mendatangi klinik kesehatan yang ada di Apotek Dhea Kuningan?

2. Layanan informasi apa saja yang ada dalam format WAP ?

3. Layanan informasi apa saja yang ada dalam format SMS gateway?

Batasan masalah dalam suatu penelitian sangat penting agar penulis tidak menyimpang dari ketentuan dan tujuan penelitian, sehingga dalam pelaksanaannya dalam hal ini penulis melakukan pembatasan masalah dalam penulisan ini yaitu :

1. Aplikasi pelayanan antrian berbasis WAP dan SMS Gateway ini terfokus pada pelayanan antrian pasien serta memberikan informasi perihal klinik kesehatan yang ada di Apotek Dhea Kuningan secara online.

2. Aplikasi WAP sebagai alternatif pendaftaran antrian dan memberikan informasi perihal klinik kesehatan yang ada di Apotek Dhea Kuningan.

3. Aplikasi SMS Gateway sebagai alternatif pengiriman antrian dan pemberitahuan waktu pemeriksaan kepada pasien.

4. Aplikasi WAP dan SMS Gateway ini menggunakan bahasa pemrograman PHP dan Mysql.

5. Aplikasi ini menggunakan tools Gammu dan database MySQL yang mendukung pelayanan sms yang berfungsi untuk menghubungkan antara operator seluler ke internet dan sebaliknya.

\section{METODE PENELITIAN}


Metode perancangan yang digunakan dalam penulisan skripsi ini melalui pendekatan metode SDLC/waterfall karena dalam penelitian ini perlu adanya pendekatan secara sistematis dan urut mulai dari level kebutuhan sistem lalu menuju ke tahap analisis, desain, coding, testing/ verification, dan maintenance. Metode ini melewati tahap demi tahap, tahap yang dilalui harus menunggu selesainya tahap sebelumnya dan berjalan berurutan ketahapan fase-fase dalam model waterfall menurut referensi Somerfille dapat dilihat pada Gambar 1.1 :

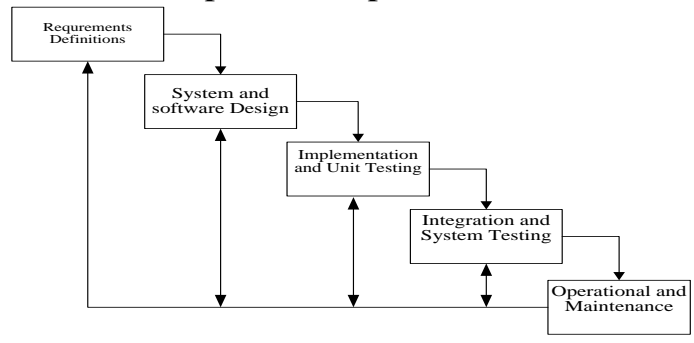

Gambar 1.1 Design Waterfall

Fase-fase model waterfall terdiri dari :

1. Requrment Definition

Tahapan ini yaitu Mendefinisikan seluruh kebutuhan sistem kemudian dianalisis dan didefinisikan kebutuhan yang harus dipenuhi oleh software yang akan dibangun.

2. System and Software Design

Proses pencarian kebutuhan diintensipkan dan difokuskan pada kebutuhan software membuat design software untuk mengetahui sifat dan rancangan program yang akan dibuat.

3. Implementation dan Unit Testing

Design program diterjemahkan kedalam kode-kode dengan bahasa pemrograman yang telah ditentukan program yang sudah dibangun baik diuji secara unit.

4. Integration dan System Testing

Tahapan ini merupakan tahapan pembuatan program dari design yang telah dirancangan dan dilakukan sebuah pengujian secara keseluruhan terhadap sistem.

5. Operational and Maintenace

Pada tahapan ini yaitu pemakaian software dan melakukan penyesuaian sistem yang telah dioperasikan, perubahan dan pengembangan dilakukan ketika ada kebutuhan dari eksternal dan pihak perusahaan dalam menyesiakan kebutuhan serta dilakukan perbaikan yang mungkin saja terdapat error yang tidak ditemukan ketika melakukan pengujian pada tahap sebelumnya.

\section{HASIL DAN PEMBAHASAN}

Berdasarkan identifikasi masalah yang telah diuraikan di atas, maka tujuan dari penyusunan ini adalah sebagai berikut :

1. Proses kerja dalam melakukan pelayanan pendaftaran antrian pasien masih manual dapat dilakukan dengan menggunakan layanan WAP dan SMS.

2. Menyajikan pelayanan pendaftaran antrian dan informasi klinik di Apotek Dhea secara Mobile yang dapat di akses setiap saat hanya dengan menggunakan ponsel.

3. Mempermudah dalam melakukan pelayanan informasi antrian untuk meningkatkan pelayanan antrian kepada pasien.

4. Meningkatkan publikasi klinik melalui WAP dan SMS.

A. Landasan Teori
Aplikasi

Aplikasi adalah suatu pengelolaan dan penggunaan program untuk memudahkan dalam pembuatan sistem informasi yang lebih cepat dan efektif atau program yang sudah jadi dan siap pakai.

( Robert Owen 1771 : Teori Manajement).

Aplikasi adalah Penggunaan program yang sudah jadi.

(Charless Babbage 1792 : Teori Manajement Klasik ).

Dari definisi di atas maka dapat disimpulkan bahwa Aplikasi adalah suatu pengelolaan dan penggunaan program untuk memudahkan dalam pembuatan sistem informasi yang lebih cepat dan efektif atau program yang sudah jadi dan siap pakai.

\section{Pengertian Antrian}

Antrian tidak hanya terjadi pada suatu sistem transportasi, namun bisa pada banyak hal dalam kehidaupan. Secara umum antrian timbul karena proses arus pergerakan orang/barang terpaksa terganggu akibat kegiatan pelayanan. Sedangkan menurut A.D. May antrian akan terbentuk ketika demand melebihi kapasitas dalam periode waktu atau jarak waktu kedatangan lurang dari waktu pelayanan(pada level mikroskopik) pada sebuah lokasi tertentu. 
Beberapa contoh antrian dalam sistem jalan raya adalah pada persimpangan, pintu tol,fasilitas parkir, penyempitan freeway, tempat kecelakaan, daerah pertemuan arus (merge area), dan dibelakang kendaraan yang bergerak lambat. Selain itu masalah antrian banyak ditemui pada kajian tentang terminal.

\section{SMS ( Short MessagService )}

SMS merupakan fitur GSM yang paling poluler hingga saat ini. Dimulai dengan diperkenalkannya sistem telepon wireless/seluler digital memberikan beberapa kelebihan, seperti kemampuan optimasi sistem yang ditunjukkan dengan kemampuan kompresi dan pengkodean data digital. Handset yang diperlukan untuk sistem ini juga menjadi sangat simpel, kecil, dan ringan, karena digunakannya chip digital untuk SIM (subscriber identification module). Teknologi chip digital juga memungkinkan penambahan fitur-fitur baru sebagai layanan tambahan, seperti voice mail, call waiting, dan short message service (SMS).

SMS dimaksudkan untuk menjadi alat pertukaran informasi antara dua mobile subscriber. Elemen-elemen utama pada arsitektur SMS terdiri dari Short Message Entity (SME), SMS Service Centre (SMSC) dan Email Gateway yang terkoneksi dengan elemenelemen pada GSM sebagai channel penghantar. Gambar 2.1 memperlihatkan arsitektur SMS pada Basic Features SMS.

\section{Pengertian WAP}

WAP adalah kependekan dari Wireless Application Protocol (WAP), WAP merupakan ponsel yang mampu memiliki konektivitas internet.

Ponsel WAP dapat digunakan untuk melakukan hal-hal seperti cek email, mengirim pesan, track saham, akses berita dan berita utama olahraga, atau download musik. Ponsel WAP tidak dapat memberikan pengalaman visual yang bagus dan seperti layanan internet di komputer desktop atau laptop. Dan hanya bisa akses internet mobile.

WAP adalah standar Internet internasional khusus dikembangkan untuk perangkat mobile, termasuk ponsel WAP, personal digital assistant (PDA) dan lainnya. Nokia, Sony Ericsson, Planet Unwired dan Motorola awalnya mengembangkan standard WAP. Banyak kekurangan pada WAP jika dibandingkan internet yaitu

1. Layar ponsel sangat terbatas,

2. Resolusi 150x150 piksel.

3. Konten Web yang paling dirancang untuk ditampilkan pada monitor dengan resolusi minimal 640x480 piksel. Sebuah ponsel juga harus bergantung pada tombol scrolling yang repot digunakan jika dibandingkan menggunakan keyboard dan mouse, dan perangkat mobile yang khusus memiliki transfer rate hanya 14,4 kilobyte per detik (kbps). Dial-up nya hanya 56kbps dengan kecepatan relatif, tetapi tidak setara dengan digital subscriber line (DSL).

4. Alamat WAP menyediakan protokol bahasa ponsel yang spesifik dan script. Grafik-grafik yang menjadi beban pada saat menggunakan WAP, hampir dieliminasi atau tidak terbuka sama sekali.

5. Konten ponsel WAP berbasis teks dan hanya diatur untuk navigasi yang mudah dengan menu bergulir. Oleh karena itu, halaman web akan muncul sangat berbeda pada ponsel WAP saat muncul di desktop komputer.

6. Mobile Internet menekankan fungsi over form yaitu memanfaatkan jejak data yang sekecil mungkin untuk mengimbangi kecepatan data yang lebih lambat dari transfernya.

7. Sementara browser mikro dari ponsel WAP kurang bagus dibandingkan dengan desktop.

\section{B. Analisis Sistem Berjalan}

Agar dapat menghasilkan sistem yang baik, tahap pertama yang harus dilakukan adalah mempelajari dan mengevaluasi sistem yang sedang berjalan. Pemahaman terhadap sistem yang sudah ada dengan mempelajari bagaimana sistem tersebut beroperasi. Adapun hal-hal yang dilakukan dalam menganalisis sistem yang sedang berjalan tersebut dengan meneliti hal-hal 
yang berhubungan dengan proses pengolahan data.

Untuk melaksanakan hal tersebut di atas, maka harus dilakukan beberapa tahapan dalam analisis sistem, yaitu :

1. Mengidentifikasi masalah, hal ini penting untuk mengetahui latar belakang dan batasan masalah.

2. Menganalisis sistem yang berjalan untuk mengetahui kemampuan sistem yang ada, ditinjau dari segi pola aliran informasi.

3. Mengevaluasi sistem yang diusulkan dan mengusulkan pemecahan masalah yang ada.

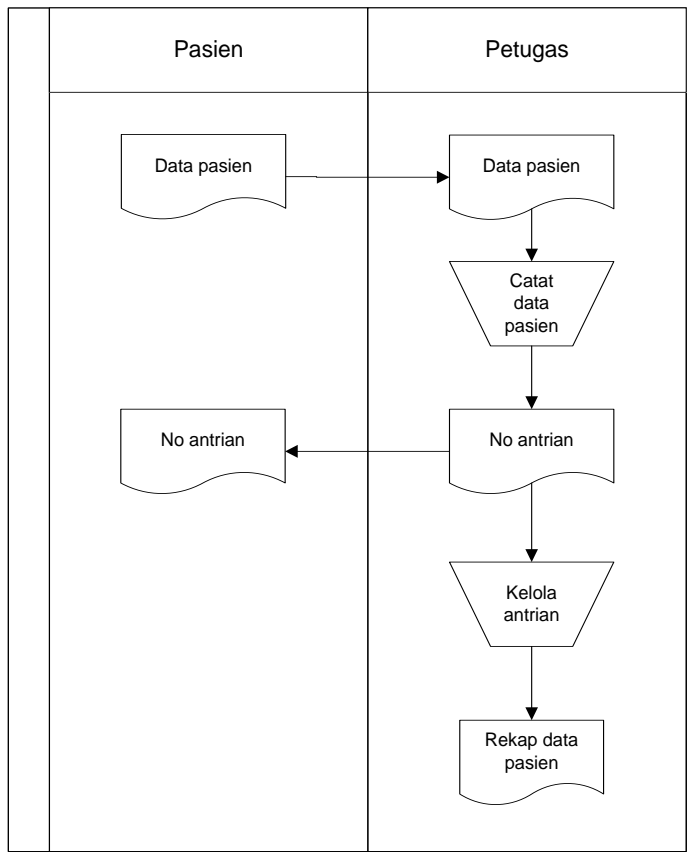

Gambar 3.1 Flowmap Analisis Sistem Berjalan

\section{Deskripsi flowmap :}

1. Pasien melakukan pendaftaran dengan memberikan data pasien kepada petugas yang kemudian petugas akan memberikan nomor antrian kepada pasien.

2. Petugas menerima pendaftaran yang berupa data pasien, kemudian petugas melakukan pencatatan data pasien yang akan menghasilkan nomor antrian. Petugas melakukan pengelolaan antrian yang akan menghasilkan rekap data pasien.

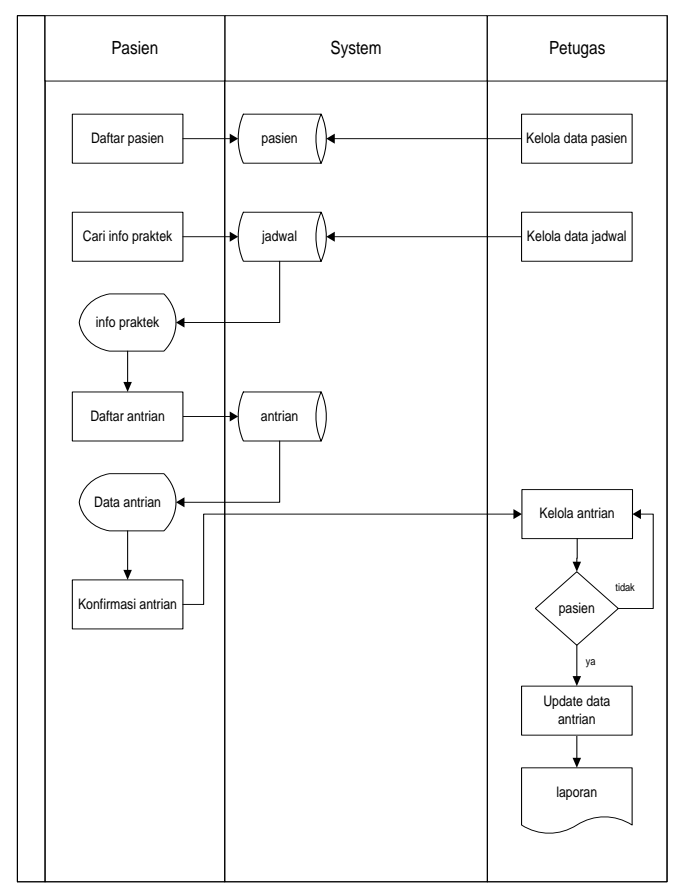

Gambar 3.4 Flowmap Sistem Diusulkan

Deskripsi flowmap sistem diajukan :

1. Pasien melakukan pendaftaran dan memperoleh info praktek melalui aplikasi WAP, kemudian akan mendapatkan data antrian yang berupa nomor antrian melalui aplikasi SMS.

2. Sistem akan menyimpan data kedalam tabel dan mengelola data.

3. Petugas mengelola data pasien, data jadwal, dan data antrian. Kemudian melakukan proses update data antrian yang menghasilkan laporan.

\section{Diagram Konteks}

Diagram konteks dibuat untuk menggambarkan sumber serta tujuan data yang akan diproses atau dengan kata lain diagram tersebut digunakan untuk menggambarkan sistem secara umum/global dari keseluruhan sistem yang ada.

Gambar 3.5 di bawah ini gambaran diagram konteks sistem informasi yang akan dibuat :

C. Analisis Sistem Diusulkan 


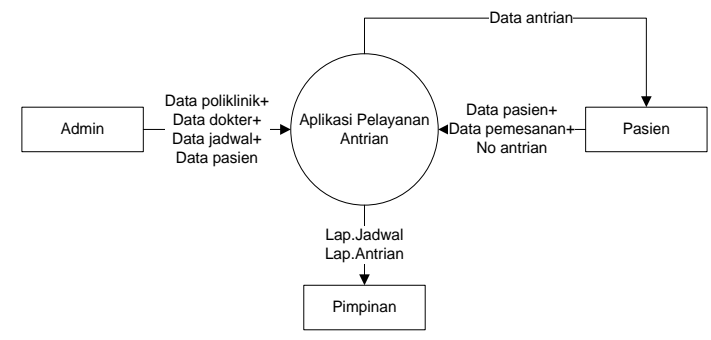

Gambar 3.5 Diagram Konteks

\section{E. Entity Relationship Diagram (ERD)}

Pada model Entity-Relationship semesta data yang ada di dunia nyata diterjemahkan menjadi sekumpulan obyek dasar yang disebut entitas (entity) dan relasi antara obyek-obyek tersebut (relationship). Kedua komponen dasar ini dideskripsikan lebih jauh melalui sejumlah atribut. Entity Relationship diagram (Diagram E-R) adalah gambaran keseluruhan struktur logis dari sebuah basis data.

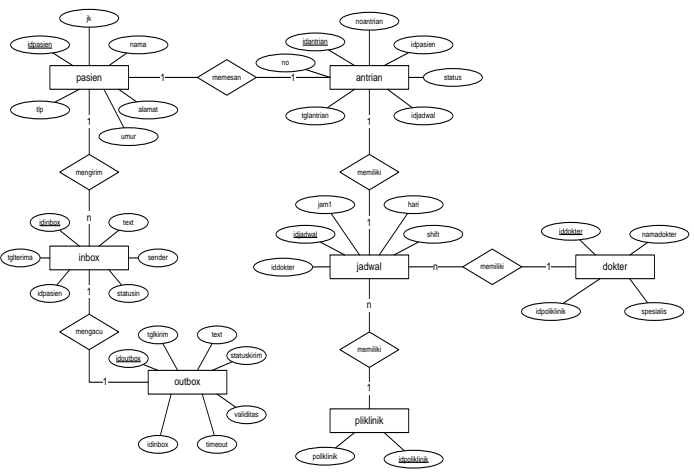

Gambar 3.7 ERD

Implementasi adalah tahap penerapan hasil perancangan yang prosesnya diuraikan sebelumnya. Implementasi yang dilakukan antara lain adalah menerapkan perancangan antarmuka ke dalam bentuk halaman web, perancangan struktur data kedalam bentuk tabel database, pembuatan kode program dan sebagainya.

\section{Antar Muka ( Interface ) Program}

Pada tahap implementasi, untuk menjalankan program yaitu dengan menjalankan web browser kemudian ketikan http://localhost/wapapotek sistem akan menampilkan tampilan index pada gambar dibawah ini.

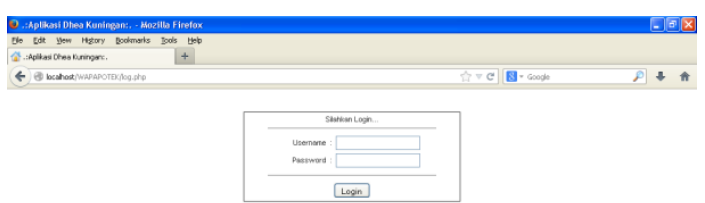

Gambar 4.2 Halaman Login

\section{Data Poliklinik}

Pada tampilan ini admin dapat melakukan pengelolaan data poliklinik. Data ini digunakan sebagai master data jurusan yang akan digunakan pada proses pemesanan antrian

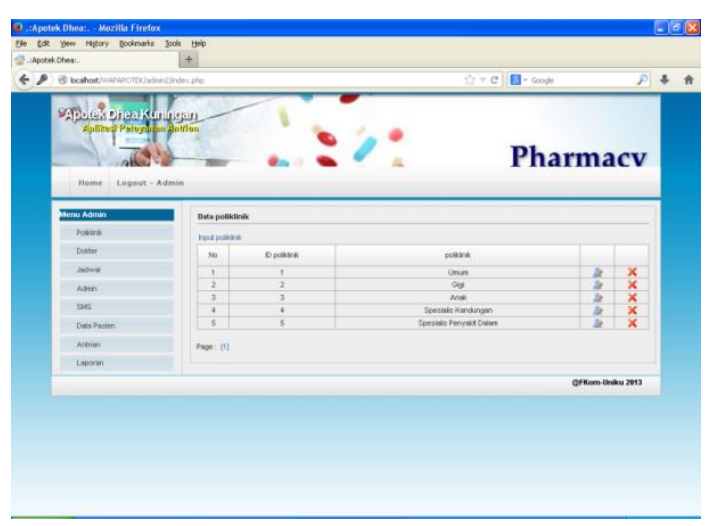

Gambar 4.3 Data Poliklinik

\section{Data Dokter}

Tampilan ini terdapat pada link yaitu dokter, admin dapat melakukan pengelolaan data dokter yang akan disimpan pada tabel dokter untuk digunakan pada proses pengelolaan data jadwal praktek.

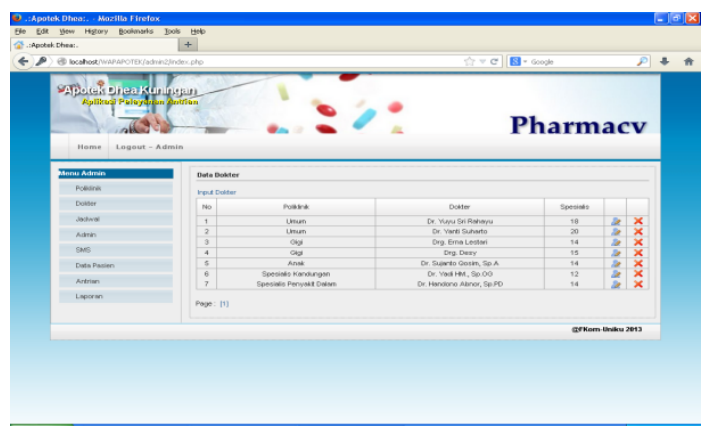

Gambar 4.4 Data Dokter 
Data Jadwal

Pada halaman ini, data jadwal digunakan untuk melakukan pengelolaan data jadwal praktek dokter yang akan pada proses pemesanan antrian.

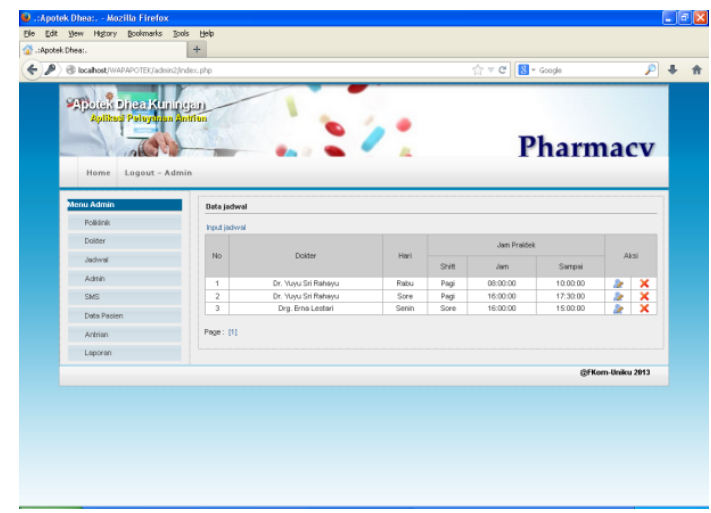

Gambar 4.5 Data Jadwal

\section{Data Antrian}

Data antrian diperoleh dari tabel antrian berupa data antrian yang telah dipesan oleh pasien. Data antrian akan ditampilkan berdasarkan jadwal antrian tertentu.

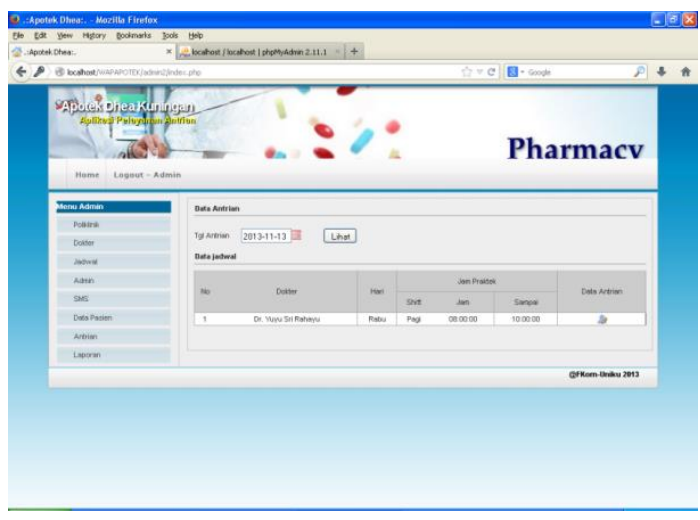

Gambar 4.6 Data Jadwal Antrian

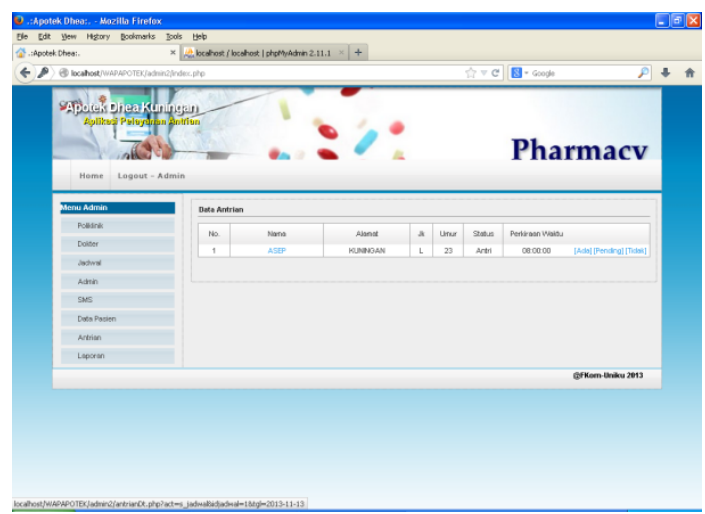

Gambar 4.7 Data Antrian

\section{Halaman WAP}

Tampilan penjadwalan akan dilakukan generate sesuai dengan data master yang telah ditentukan.

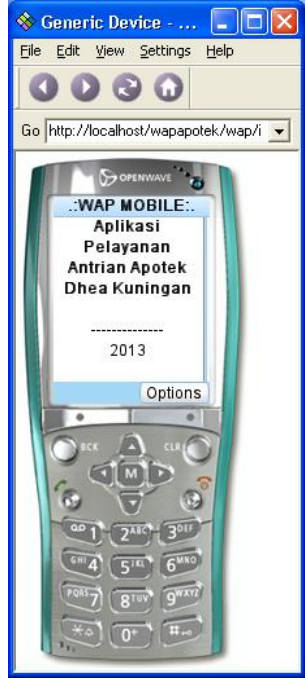

Gambar 4.8 Halaman WAP

\section{KESIMPULAN}

Adapun kesimpulan yang diperoleh dari hasil penelitian yang telah dilakukan adalah sebagai berikut :

1. Sistem yang dibuat memberikan kemudahan terhadap proses pengelolaan data pemesanan antrian yang sudah terintegrasi dengan database sehingga lebih mudah dan efektif,

2. Sistem yang dibuat mampu memberikan informasi dan kemudahan kepada user atau pasien melalui aplikasi WAP user memperoleh info praktek dan kemudian akan mendapatkan data antrian berupa nomor antrian melalui aplikasi SMS 
3. Sistem yang dibuat dapat memperluas pemasaran karena mudahnya akses terhadap data antrian, dengan adanya lanyanan WAP publikasi pelayanan antrian ini dapat menyebar dengan mudah yang dapat berpengaruh pada perluasan pemasaran

4. Proses pembuatan laporan menjadi mudah karena adanya sistem yang terintegrasi dengan database.

\section{SARAN}

Setelah penulis mengadakan penelitian, maka ada beberapa saran yang ingin penulis kemukakan agar sistem berjalan maksimal, antara lain:

1. Untuk mengoperasikan program aplikasi ini, diperlukan adanya pelatihan khusus terlebih dahulu terhadap user.

2. Untuk menghasilkan program aplikasi yang baik, diperlukan ketelitian dalam penelitian, perancangan, dan pengkodean.

3. Data yang telah terkomputerisasi diharapkan merupakan data yang up to date.

4. Pengisian data untuk semua format masukan harus dilakukan dengan teliti sehingga informasi yang dihasilkan sesuai dengan yang diharapkan.

5. Dalam pembuatan aplikasi ini masih banyak sekali kekurangan, oleh karena itu diperlukan adanya pengembangan yang lebih lanjut.

\section{DAFTAR PUSTAKA}

[1] Fathansyah, (1995). Pengertian Entity Relationship Diagram http://www.academia.edu/4053549/BAB I

[2] Gordon B. Davis, ( 1974 ), Management Informations System : Conceptual Foundations, Strctures, and Development, McGrawHill Kogakusha.

[3] Harianto, Bangbang. (2004). Sistem manajemen basisdata: Pemodelan, perancangan dan ? Bandung: Informatika

[4] Jogiyanto, Hartono. MBA. Ph.D (2001). Analisis dan Desain Sistem Informasi.Yogyakarta: Andi

[5] M.J Alexander, (1982), Information System Analysis : Theory and Application

[6] Pengertian Antrian (online) http://armandjexo.blogspot.com/2012/04/te ori-antrian.html 